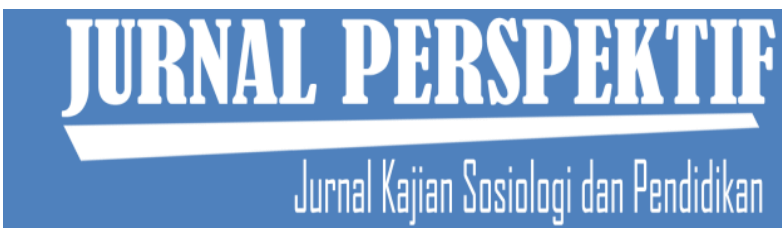

Jurnal Perspektif: Jurnal Kajian Sosiologi dan Pendidikan

Vol. 2 No. 3 Tahun 2019

http://perspektif.ppj.unp.ac.id

Email: perspektif@ppj.unp.ac.id

ISSN: 2622-1748 (Online), 2684-902X (Print)

DOI: http://dx.doi.org/10.24036/perspektif.v2i3.80

\title{
Semiotik Panggilan Pasutri Pada Kalangan Remaja di Daerah Pasaman Barat
}

\author{
Uli Arta Meritua Samosirl, Mira Hasti Hasmira ${ }^{2}$ \\ 1,2Universitas Negeri Padang \\ Email: uliartamerituasamosir@gmail.com, mirahasti@fis.unp.ac.id
}

\begin{abstract}
Abstrak
Penelitian ini dilatarbelakangi oleh ketertarikan peneliti dalam melihat penggunaan panggilan pasutri di kalangan remaja yang berpacaran di daerah Pasaman Barat. Penelitian ini bertujuan untuk menjelaskan makna dari panggilan pasutri. Penelitian ini menggunakan kajian semiotik berdasarkan kajian semiotik model Charles Sanders Peirce. Teknik pemilihan informan menggunakan purposive sampling dengan jumlah informan 35 orang informan. Pengumpulan data dilakukan dengan cara observasi, wawancara dan dokumentasi yang dianalisis dengan menggunakan model triangle meaning semiotics. Hasil penelitian ini menunjukkan bahwa makna dari penggunaan panggilan pasutri di kalangan remaja yang berpacaran di Pasaman Barat yaitu ketika punya pacar, maka harus memiliki panggilan spesial. Ketika merasa rindu dan lelah harus diungkapkan dengan menggunakan panggilan pasutri agar apa yang dirasakan dapat tercurahkan. Selain itu makna panggilan pasutri yaitu panggilan pasutri dalam sebuah hubungan dapat meningkatkan keakraban atau kedekatan antara perempuan dan laki-laki yang sedang berpacaran. Dan yang terakhir makna dari panggilan pasutri yaitu ketika seseorang menggunakan panggilan pasutri pada saat berpacaran, maka hubungan mereka merupakan suatu hubungan pacaran yang serius. Selain itu penggunaan panggilan pasutri pada saat berpacaran ini juga dapat meningkatkan keseriusan dalam menjalin suatu hubungan.
\end{abstract}

Kata Kunci : Remaja, Berpacaran, Panggilan pasutri

\begin{abstract}
This research is motivated by the interest of researchers in looking at the use of pasuti's callsin teenagers who are dating in the West Pasaman area. This study aims to explain the meaning of pasutri's calls in teenagers who are dating. This study uses the semiotic method of Charles Sanders Peirce's model. The informant selection technique used purposive sampling with the number of informants are 20 informants who used the pasutri's calls in dating, 5 people who were not dating, and 5 parents whose children were dating using pasutri's calls. Data collection by observation, interview and documentation. This study was analyzed using triangle meaning semiotic's model. The results showed that the meaning of pasutri's calls inteenagers who are dating in West Pasaman, when having a boyfriend must have a special call. When feel missed and tired, by using a pasutri's call, then that feeling can be revealed. In addition, the meaning of pasutri's calls in a relationship can increase the harmony of lovers. The last meaning of pasutri's call, which can increase the seriousness in a relationship.
\end{abstract}

Keywords: Teenagers, Dating, pasutri's call

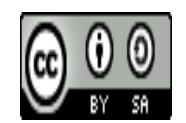

Received: July 23, $2019 \quad$ Revised: July 26, 2019 Available Online: July 29, 2019

\section{Pendahuluan}

Jurnal Perspektif: Jurnal Kallan Soslologl dan Pendidlkan Vol. 2, No. 3, Th. 2019

ISSN. 2622-1748 
Cinta pada umumnya sudah ada dalam diri tiap individu, dimulai dari cinta terhadap sesuatu di sekitar individu tersebut seperti cinta pada orang tua, teman dan cinta pada lawan jenis. Sikap cinta pada seseorang dapat dilihat dari perilaku, perasaan, dan pola berpikirnya dalam menjalani kehidupan sehari-hari, sehingga menyebabkan perbedaan setiap orang dalam menyikapi cinta dan menjadikan teori tentang cinta menjadi berbeda-beda. Cinta dapat terlihat pada beberapa sisi di dalam kehidupan seperti sikap, emosi, dan perilaku pada seseorang yang sedang jatuh cinta (Puhi, 2018). Saat seseorang jatuh cinta maka mereka biasanya ingin selalu dekat dengan orang yang dicintainya, senang ketika berbicara dengan orang yang dicintai dalam waktu yang lama, sering merasa rindu jika lama tidak bertemu, ingin membahagiakan orang yang ia cintai, dan ingin selalu ada untuknya. Bentuk pengungkapan rasa cinta yang timbul dalam diri individu berbeda-beda, salah satunya adalah dengan berpacaran.

Hubungan pacaran itu bisa muncul ketika kita merasakan daya tarik seksual terhadap seseorang, sehingga kita akan meluangkan waktu dengan orang tersebut. Datting atau yang biasa dikenal dengan istilah pacaran dapat dijelaskan bagaimana seseorang menjalankan suatu hubungan, dimana dua orang yang berlawanan jenis bertemu dan melakukan beragam aktivitas secara bersama-sama agar dapat saling mengenal satu sama lain (Daud, 2016). Ketika kita menemukan bahwa kita memiliki persamaan dengan orang tersebut, kita dapat memberikan label "cinta" pada perasaan tersebut, dan kita menggambarkan diri kita sedang "jatuh cinta" (M.Henslin, 2007). Pacaran biasa dilakukan oleh seorang wanita dan pria yang sedang jatuh cinta. Pada masa kini pacaran tidak hanya dilakukan oleh seseorang yang ingin melanjutkan hubungan ke arah yang lebih serius, melainkan pacaran juga telah dilakukan oleh beberapa kalangan, salah satu diantaranya yaitu remaja.

Fenomena pacaran ini sudah tak asing lagi dikalangan remaja. Pada sekolah menengah pertama dan sekolah menengah atas cukup banyak siswa yang ditemukan berpacaran, meskipun ada beberapa sekolah yang telah memberikan peraturan bahwa semua siswanya dilarang untuk berpacaran, dan apabila ada yang ditemukan berpacaran, maka akan diberikan sanksi. Salah satu sekolah yang menerapkan peraturan tersebut yaitu SMPN 1 Luhak Nan Duo. Ada beberapa siswa yang peneliti temukan di lapangan yang ketahuan berpacaran dan diberikan sanksi dari pihak sekolah yaitu dengan memanggil kedua orang tua siswa tersebut, namun hal itu tidaklah membuat para siswa lainnya yang berpacaran ataupun siswa yang telah ketahuan tersebut takut ataupun jera.

Menurut mereka berpacaran adalah hal yang biasa dikalangan remaja, dan apabila tidak memiliki seorang pacar maka akan di katakan ketinggalan zaman, tidak kekinian, tidak laku atau jomblo. Dikalangan remaja, status jomblo merupakan suatu hal yang cukup menyedihkan, dikarenakan mereka akan dikatakan sebagai seseorang yang tidak laku. Menurut KBBI jomblo berasal dari kata jom-lo yang berarti gadis tua. Kata ini digunakan untuk menyebut perempuan yang sudah tua namun belum menikah atau memiliki pasangan. Kata jomlo sendiri ditambahi dengan huruf b, sehingga kata jomlo menjadi jomblo. Seiring dengan perkembangan zaman kata jomblo mengalami perluasan makna yang berarti perempuan atau laki-laki yang tidak memiliki pasangan.

Didaerah Pasaman Barat dapat peneliti temukan remaja yang berpacaran satu sekolah ataupun beda sekolah, selain itu juga cukup banyak dapat ditemukan remaja yang berpacaran dengan remaja lainnya yang tidak bersekolah yang menggunakan panggilan sayang untuk kekasihnya. Panggilan sayang yang digunakanpun beragam, ada yang menggunakan panggilan sayang yang diambil dari fisik pasangannya seperti kiting(itingku) dan membot (mbot), ada yang diambil berdasarkan usia pasangannya, namun ada juga yang tidak kalah fenomenal yaitu panggilan sayang papa mama dan sejenisnya. 
Panggilan papa mama dan sejenisnya itu, biasanya digunakan oleh seorang anak untuk memanggil orang tua laki-laki yang disebut papa dan orang tua perempuan yang disebut mama. Selain digunakan oleh seorang anak kepada orang tuanya, panggilan ini biasanya juga digunakan bagi orang tua tersebut untuk memanggil pasangannya, hal ini bertujuan untuk mensosialisasikan kepada anaknya panggilan apa yang seharusnya digunakan seorang anak untuk kedua orang tuanya. Namun kenyataannya panggilan ini juga digunakan oleh anak remaja yang sedang berpacaran.

Berdasarkan hasil observasi dan angket siswa didapatkan hasil, dari 45 angket yang disebar di 3 sekolah yang berbeda kecamatan dari jumlah keseluruhan kecamatan yaitu 11, maka ditemukan 35 remaja yang menggunakan panggilan pasutri sebagai panggilan spesialnya dan 10 remaja yang menggunakan panggilan lain. Panggilan yang biasa digunakan pasutri ini, digunakan mereka dalam berkomunikasi dengan pasangannya menjadi sebuah simbol bagi mereka saat melakukan komunikasi. Simbol-simbol atau tanda-tanda yang digunakan dalam berkomunikasi bukanlah tidak berarti apa-apa, didalamnya ia mengemban sebuah makna yang dapat digali kandungan faktualnya dengan kata lain bahasa simbolis tersebut menciptakan situasi yang simbolis pula, artinya penuh dengan tanda tanya atau halhal yang mesti diungkap maksud dan arti yang terkandung dalam simbolnya (Adityo, 2012).

Simbol memiliki dua komponen penting yaitu tanda dan makna. Setiap tanda tentu memiliki makna yang berbeda, setiap orang juga memiliki makna yang berbeda terhadap suatu tanda yang ada. Panggilan papa dan mama dapat dimaknai oleh sebagian orang sebagai suatu panggilan yang biasa digunakan oleh orang yang telah menikah, namun tidak bagi remaja yang sedang berpacaran, panggilan papa dan mama ini memiliki makna tersendiri bagi mereka. Dalam hal ini, studi semotik dapat membantu untuk menjelaskan kasus tersebut, karena studi semiotik atau semiotika merupakan ilmu tentang tanda dan makna dari sistem tanda. Tanda itu sendiri adalah sesuatu yang bagi seseorang merujuk pada sesuatu yang lain berdasarkan landasan tertentu. Jadi penelitian semiotika ini menemukan sebuah makna yang tersembunyi (laten) bukan makna yang sudah jelas ada.

Penelitian ini bertujuan untuk mengetahui bagaimana makna penggunaan panggilan pasutri berdasarkan kajian studi semiotik yang digunakan remaja yang berpacaran di daerah Pasaman Barat. Penelitian ini dianalisis oleh teori segitiga makna yang dikemukakan oleh Charles Sanders Pierce yang menjelaskan bahwa untuk mengetahui atau menjelaskan suatu makna, maka diperlukan sebuah tanda dan sesuatu yang dirujuk oleh tanda tersebut. Dalam teori ini ketiga hal tersebut saling berhubungan satu dengan yang lainnya (Vera, 2014).

\section{Metode Penelitian}

Penelitian ini menggunakan pendekatan kualitatif dengan tipe semiotika. Tipe penelitian ini mampu menganalisis makna dari tanda-tanda yang ada dalam permasalahan penelitian. Model semiotika yang digunakan yaitu model Charles Sanders Peirce yang dikenal dengan model triadic atau triangle meaning semiotics. Tipe penelitian ini digunakan karena mampu membantu peneliti menganalisis makna penggunaan panggilan pasutri yang ada di dalam permasalahan penelitian. Informan dalam penelitian ini yaitu remaja yang menggunakan panggilan pasutri di daerah Pasaman Barat, remaja yang tidak berpacaran, orang tua dari remaja yang menggunakan panggilan pasutri, dan masyarakat yang berada di daerah tempat tinggal remaja yang menggunakan panggilan pasutri. Teknik pemilihan informan yang digunakan adalah purposive sampling dengan jumlah informan 35 orang.Untuk menentukan informan selanjutnya, peneliti mengalami kesulitan sehingga peneliti juga menggunakan teknik snowball dengan menggunakan informan kunci. Informan 
yang menjadi informan kunci dalam penelitian ini yaitu Tika, Indah, Tari, Putri, Amel, Radot, Edo. Metode pengumpulan data yang digunakan yaitu pengamatan (observasi partisipasi pasif), wawancara mendalam dan studi dokumentasi. Penelitian ini dianalisis dengan menggunakan teknik analisis semiotika oleh Charles Sanders Pierce dengan model triadic yang didalamnya terdapat 3 unsur pokok yaitu representament, interpretant, dan object.

\section{Hasil dan Pembahasan}

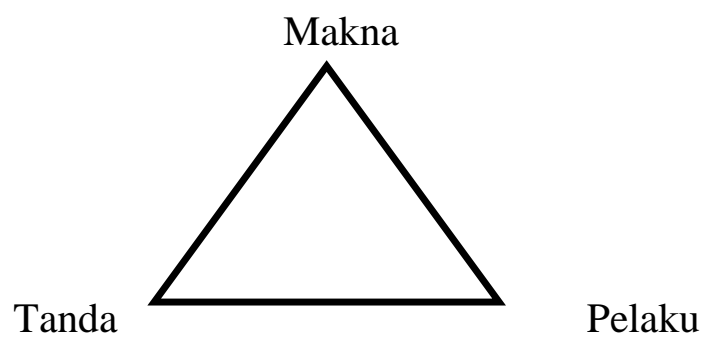

Pada bagian ini akan dikemukakan hasil penelitian tentang Makna Panggilan Pasutri Pada Kalangan Remaja di Daerah Pasaman Barat. Untuk mengetahui makna dari penggunaan panggilan pasutri yang digunakan oleh remaja di daerah pasaman barat, maka peneliti melakukan observasi dan wawancara kepada remaja, orang tua dan masyarakat sekitar. Makna penggunaan panggilan pasutri pada kalangan remaja ini dianalisis dengan teori segitiga makna oleh Charles Sanders Pierce yang mana mengatakan bahwa Representament (tanda), Object (pelaku) dan Interpretant (makna) ketiga hal tersebut saling berkaitan satu dengan yang lainnya dan saling berhubungan serta tidak bisa dipisahkan satu dengan yang lainnya (Vera, 2014). Sehingga untuk mengetahui salah satu dari ketiga hal tersebut, maka diperlukan unsur lainnya agar dapat menemukan unsur yang ingin diketahui. Remaja di daerah Pasaman Barat yang menggunakan panggilan pasutri ini memiliki ketiga hal tersebut, berikut penjelasannya :

\section{Pelaku}

Pelaku yang menggunakan panggilan pasutri yang menjadi informan dalam penelitian ini sebanyak 20 orang. Pelaku atau object dalam penelitian ini merupakan remaja yang menggunakan panggilan pasutri sebagai panggilan spesial pada daerah Pasaman Barat dari berbagai etnis dan agama, yaitu Jawa, Minang, dan Batak. Pelaku yang merupakan remaja di daerah Pasaman Barat ini menggunakan panggilan pasutri setiap berpacaran dengan lawan jenisnya. Adapun panggilan yang mereka gunakan dengan pasangannya saat ini maupun dengan pasangannya sebelumnya tidaklah sama. Mereka memberikan panggilan yang berbeda, akan tetapi panggilan yang digunakan masih seputaran panggilan pasutri seperti abi umi, papa mama, ayah bunda dan bojo. Remaja di daerah ini yang merupakan object atau pelaku yang menggunakan panggilan pasutri sebagai panggilan spesialnya, menganggap bahwa hal tersebut merupakan hal yang wajar dalam berpacaran. Hal ini dikarenakan banyak teman-teman seusia mereka yang menggunakan panggilan pasutri sebagai panggilan spesial dalam berpacaran.

Di dalam teori segitiga makna oleh Charles Sanders Pierce ini terdapat tiga unsur pokok yaitu Representament atau yang biasa disebut sebagai tanda, object dan juga interpretant atau makna. Ketiga unsur pokok tersebut saling berkaitan satu dengan yang lainnya (Vera, 2014). Informan diatas beserta pasangannya dapat dikatakan sebagai object (pelaku) karena ia mengandung unsur yaitu, ia menciptakan tanda (Representament) yang berupa panggilan pasutri sebagai panggilan spesial dalam status pacarannya dan ia merupakan sesuatu yang 
dirujuk oleh tanda tersebut. Selain itu informan juga terbiasa menggunakan panggilan spesial tersebut ketika menjalin suatu hubungan pacaran bersama pasangan sebelumnya. Kemudian di dalam tanda yang diciptakan oleh object (informan) tersebut juga memiliki makna (Interpretant) yang ada dalam benaknya dan merupakan hasil hubungan antara representament (Tanda) dengan object. Hal inilah yang menyebabkan informan dapat dikatakan sebagai pelaku (object) dalam penelitian ini.

\section{Tanda}

Tanda yang digunakan remaja di daerah Pasaman Barat yaitu tanda berupa panggilan yang dimiliki oleh pelaku (informan) dalam status hubungan pacaran mereka. Adapun tanda berupa panggilan yang mereka gunakan yaitu panggilan pasutri. Remaja di daerah ini menggunakan panggilan pasutri sebagai panggilan spesial mereka dengan pasangannya. Hal ini dilakukan karena menurut mereka panggilan ini merupakan suatu panggilan yang romantis dibandingkan dengan panggilan lainnya. Selain itu panggilan ini digunakan juga sebagai tanda bahwa mereka memiliki status berpacaran. Dengan adanya panggilan ini, orang-orang akan tahu bahwa mereka memiliki suatu hubungan spesial atau yang biasa disebut sebagai pacaran.

Berdasarkan hasil wawancara peneliti dengan informan, peneliti kemudian menganalisis data yang didapatkan menggunakan teori segitiga makna. Didalam teori itu terdapat representament, object, dan interpretant, ketiga hal tersebut berhubungan dan memiliki kaitan antara satu dengan yang lainnya. Pelaku (object) disini menciptakan tanda dan memiliki makna yang ada di dalam benaknya (Vera, 2014). Yang menjadi object dalam penelitian ini yaitu informan yang menggunakan panggilan pasutri tersebut. Adapun tanda yang diciptakan oleh object yaitu berupa penggunaan panggilan pasutri yang ia gunakan ketika berkomunikasi dengan pasangannya. Disini mereka menggunakan panggilan pasutri tersebut sebagai tanda bahwa mereka memiliki hubungan pacaran sehingga orang-orang disekitar mereka dapat mengetahui bahwa mereka memiliki hubungan spesial yaitu berupa hubungan pacaran. Hal itulah yang menyebabkan panggilan pasutri menjadi interpretant atau sebuah tanda dalam teori segitiga makna ini.

\section{Makna}

Makna atau Interpretant yang terdapat dalam masalah penelitian ini dapat dibagi menjadi dua, yaitu makna dari pacaran dan makna panggilan pasutri menurut informan (Object).

\section{Makna Pacaran}

Pacaran merupakan suatu fase dimana seseorang menjalin suatu hubungan untuk mengenal satu dengan yang lainnya agar dapat menentukan hubungan selanjutnya ke arah yang lebih serius. Pacaran sendiri memiliki makna, dan makna itu bagi beberapa orang memiliki perbedaan. Makna pacaran bagi remaja di Daerah Pasaman Barat setelah dianalisis dengan menggunakan teori segitiga makna oleh Charles Sanders Pierce yaitu makna pacaran bagi remaja yaitu sebuah hubungan pacaran merupakan hubungan yang serius, remaja yang berpacaran menganggap bahwa dirinya telah dewasa dan siap untuk menjalin hubungan ke jenjang yang lebih serius. status pacaran dikalangan remaja merupakan suatu hal yang penting dan membanggakan, serta akan dianggap aib jika tidak memiliki pasangan (jomblo). makna ketika remaja berpacaran mereka rajin kesekolah dikarenakan ada yang memberi semangat artinya pacaran bagi mereka merupakan salah satu moodboster dan salah satu motivasi mereka dalam belajar. 
Adapun makna pacaran lainnya yaitu ketika berpacaran remaja harus mempublikasikan hubungan mereka kepada teman-temannya dikarenakan hal tersebut merupakan suatu hal yang membanggakan. Selain itu, makna pacaran bagi remaja dapat dimaknai bahwa ketika berpacaran remaja tidak hanya menjadikan pacarnya sebagai tempat untuk mencurahkan perasaan cintanya melainkan juga sebagai tempat untuk mecurahkan isi hati dan sebagai tempat untuk bertukar pikiran dan tempat untuk berdiskusi.

\section{Makna Panggilan Pasutri}

Makna dari panggilan pasutri bagi pelaku (object) dapat di lihat dan ditafsirkan melalui wawancara peneliti dengan pelaku (object). Adapun akna panggilan pasutri bagi pelaku (object) yaitu ketika memiliki pacar, maka harus memiliki panggilan spesial. Selain itu juga memiliki makna bahwa ketika menggunakan panggilan pasutri pada saat berpacaran dapat melatih diri agar terbiasa menggunakan panggilan tersebut sehingga ketika menikah nantinya tidak menjadi hal yang baru lagi karena telah terbiasa dengan panggilan tersebut sebelumnya. Kemudian panggilan pasutri juga memiliki makna bahwa ketika merasa rindu atau kangen dengan pasangan harus diungkapkan dengan menggunakan panggilan pasutri agar rindu yang dirasakan dapat tercurahkan kepada pasangannya.

Adapun makna panggilan pasutri lainnya yaitu ketika merasa capek atau lelah, memanggil pasangan dengan panggilan pasutri dapat menghilangkan rasa lelah yang dirasakan pada saat itu. Makna panggilan pasutri lainnya yaitu ketika ingin bermanja-manja dengan pacar, maka harus menggunakan panggilan pasutri agar dapat dimanjakan oleh pacarnya. Selain itu makna panggilan pasutri yaitu panggilan pasutri dalam sebuah hubungan dapat meningkatkan keakraban atau kedekatan antara perempuan dan laki-laki yang sedang berpacaran. Dan yang terakhir makna dari panggilan pasutri yaitu ketika seseorang menggunakan panggilan pasutri pada saat berpacaran, maka hubungan mereka merupakan suatu hubungan pacaran yang serius. Selain itu penggunaan panggilan pasutri pada saat berpacaran ini juga dapat meningkatkan keseriusan dalam menjalin suatu hubungan.

\section{Kesimpulan}

Berdasarkan hasil penelitian yang peneliti lakukan dan telah dianalisis. Maka dapat diketahui bahwa pacaran merupakan hal yang penting bagi remaja di daerah Pasaman Barat. Selain itu juga dapat diketahui makna panggilan pasutri bagi remaja di daerah ini secara umum, yaitu panggilan pasutri boleh digunakan sebagai panggilan spesial. Sedangkan makna panggilan pasutri secara khusus bagi remaja di daerah Pasaman Barat yaitu ketika memiliki pacar, maka harus memiliki panggilan spesial. Ketika merasa rindu, lelah, ingin bermanjamanja dengan pasangan harus diungkapkan dengan menggunakan panggilan pasutri agar apa yang dirasakan dapat tercurahkan. Selain itu makna panggilan pasutri yaitu panggilan pasutri di dalam sebuah hubungan dapat meningkatkan keakraban atau kedekatan antara sepasang kekasih. Dan yang terakhir makna dari panggilan pasutri yaitu ketika seseorang menggunakan panggilan pasutri pada saat berpacaran, maka hubungan mereka merupakan suatu hubungan pacaran yang serius dapat meningkatkan keseriusan dalam menjalin suatu hubungan. 


\section{Daftar Pustaka}

Adityo, W. (2012). Pemaknaan Ilustrasi Sampul Buku "Poconggg Juga Pocong” ( Studi Semiotik Ilustrasi Sampul Buku " Poconggg Juga Pocong ” Pada ”Bukune ”).

Daud, M. (2016). Perilaku Pacaran Dikalangan Pelajar SMP Negeri Satu Belat Di Desa Penarah Kecamatan Belat Kabupaten Karimun. 1-30.

M.Henslin, J. (2007). Sosiologi Dengan Pendekatan Membumi. Jakarta: Erlangga.

Puhi, S. R. N. I. (2018). Perbedaan Gaya Cinta Ditinjau dari Tahap Perkembangan Remaja.

Vera, N. (2014). Semiotika Dalam Riset Komunikasi. Bogor: Ghalia Indonesia. 